\title{
Psychosocial functioning in adolescents growing up with chronic disease: The Dutch HBSC study
}

\author{
Emma E. Berkelbach van der Sprenkel ${ }^{1}$ (D) Sanne L. Nijhof ${ }^{1}$. Geertje W. Dalmeijer ${ }^{2} \cdot$ N. Charlotte Onland-Moret ${ }^{2}$. \\ Simone A. de Roos ${ }^{3} \cdot$ Heidi M. B. Lesscher ${ }^{4}$. Elise M. van de Putte ${ }^{1}$. Cornelis K. van der Ent ${ }^{6}$. Catrin Finkenauer ${ }^{5}$. \\ Gonneke W. J. M. Stevens ${ }^{5}$
}

Received: 15 March 2021 / Revised: 29 August 2021 / Accepted: 17 September 2021 / Published online: 30 September 2021

(c) The Author(s) 2021

\begin{abstract}
Many adolescents worldwide (indirectly) grow up with a chronic disease, which may impact their functioning and wellbeing. The objective of this study is to assess whether adolescents with a (family member with a) chronic disease differ from their healthy counterparts in terms of psychosocial functioning. Data from the Dutch 2013 HBSC-survey were used, including 7168 adolescents $\left(\right.$ Mean $_{\mathrm{age}}=13.7, \mathrm{SD}=1.57,50.5 \%$ female). Participants indicated whether they or one of their family members had a long-term ( $>3$ months) disease or disability (mental/physical) and were categorized into four groups based on disease presence (none, other, self, both). Psychosocial functioning was assessed in terms of life satisfaction, self-rated health, psychosomatic health, mental health problems, support, substance use, physical exercise, screen time, and school liking. Chronically diseased adolescents $(n=162)$ reported lower life satisfaction, self-rated and psychosomatic health, more mental health problems, lower peer support, more substance use, and less physical exercise compared to healthy peers. Chronically diseased adolescents who also had a family member with a chronic disease $(n=74)$ showed comparable outcomes on these life domains, although they did not differ from their healthy peers regarding peer support, substance use, and physical activity. Healthy adolescents with a chronically diseased family member $(n=737)$ reported significantly lower life satisfaction, self-rated and psychosomatic health, more mental health problems, and less family support compared to healthy peers who grew up in healthy families; however, they reported more positive outcomes than adolescents who had a chronic disease themselves.

Conclusion: Having a (family member with a) chronic disease is associated with impaired psychosocial functioning on various life domains. Our findings aid in understanding the psychosocial associates of chronic disease and imply that caregivers should be observant of psychosocial problems among vulnerable adolescents to provide appropriate guidance.

\section{What is Known:}

- Adolescents who grow up with a (family member with a) chronic disease encounter numerous challenges that may be related to poorer developmental outcomes on the long term.

What is New:

- This study adds a comprehensive overview of the psychosocial functioning of adolescents with a (family member with a) chronic disease, as compared to healthy counterparts that grow up in a healthy family.
\end{abstract}

Keywords Adolescents $\cdot$ Chronic disease $\cdot$ Psychosocial $\cdot$ Functioning

\section{Abbreviations}

FAS Family Affluence Scale

HBSC Health Behavior in School-aged Children

\section{Communicated by Peter de Winter}

Gonneke W. J. M. Stevens

g.w.j.m.stevens@uu.nl

Extended author information available on the last page of the article
SDQ Strengths and Difficulties Questionnaire

SES Socio-Economic Status

\section{Introduction}

The progress made in the treatment of pediatric chronic diseases is revolutionary [1]. Many chronic childhood diseases, such as auto-immune disorders, congenital heart 
disease, and childhood cancer, can now be stabilized or even cured [1-4]. As a result, the percentage of children growing up with a chronic disease has increased considerably, with increases from $12.8 \%$ in 1994 to $26.2 \%$ in 2006 in the USA $[1,5]$. Recent Dutch research has shown that $26 \%$ of the children and young adults under the age of twenty-five suffer from a chronic disease, which adds up to a total of more than 1.3 million in the Netherlands [6]. This poses novel challenges for healthcare providers in delivering care for chronically ill children, adolescents, and their families.

Growing up with a chronic disease may impact the psychosocial functioning of the individual and family functioning beyond the actual illness itself [4, 7-10]. Particularly during adolescence, the period of physical and emotional maturation, socialization, and identity formation, management of a chronic disease may constitute a major challenge [11]. Adolescents with a chronic disease experience physical disabilities, periods of hospitalization, disease-related symptoms (such as pain or fatigue), stressful situations, and emotional distress [9, 12]. Related to this, mental health problems, impaired social functioning, and stigmatization have been observed in adolescents with chronic physical conditions [9, 12-15]. Besides that, elevated levels of internalizing and externalizing problems have been found within this population [16]. Retrospective research has indicated that young adults with pediatric chronic illness are less successful in achieving developmental milestones compared to healthy peers [12]. Thus, research suggests that chronic disease affects adolescent functioning in a variety of life domains, yet a comprehensive picture of which life domains are affected and to what extent is lacking.

Rather than being limited to the individual patient, chronic disease of a family member may have spillover effects to other family members. It may impact family functioning in terms of physical, emotional, social, and financial stress and may affect daily activities—like caregiving — and family dynamics [17-20]. For example, having a chronically ill parent is related with increased stress, internalizing problems, substance use, and risk of poorer developmental outcomes for adolescents [21-26]. Similarly, siblings of chronically ill children have been found to be at increased risk for psychosocial problems and impaired cognitive and academic development [27-29]. Although spillover effects of chronic disease have been recognized, to our knowledge, there is a lack of studies that compare psychosocial functioning of healthy adolescents with that of adolescents with a chronic disease themselves and/or with a family member with a chronic disease.

Notwithstanding the previous, there are large interindividual differences in adolescents' resilience, and not all adolescents with a chronic disease experience negative consequences. It is therefore of paramount importance to better understand the interplay between chronic illness and psychosocial functioning among adolescents [8]. The objective of this study is to assess whether and how adolescents with a (family member with a) chronic disease differ from their healthy counterparts. Specifically, we distinguished four groups of adolescents: adolescents from healthy families (in the following labelled as none), adolescents with a chronically diseased parent or sibling (other), adolescents suffering from a chronic disease themselves (self), and chronically diseased adolescents with a chronically diseased parent or sibling (both). By comparing healthy and diseased adolescents in families with or without family members that suffer from a chronic disease, we can discriminate between associations that are specific to one's own or family disease. Based on the available empirical research, we hypothesized that compared to no disease, both having a chronic disease and having a family member with a chronic disease is associated with increased psychosocial distress on virtually all life domains. Insights in adolescents' own perception of their social context and functioning across different life domains are indispensable for effective preventative or therapeutic strategies to improve coping and resilience.

\section{Methods}

\section{Participants}

Data were used from the 2013 Dutch Health Behavior in School-aged Children (HBSC) survey, which is a large, representative survey on the health, wellbeing, and social context of Dutch adolescents in the age of 11-16 years [30]. A randomized sample was drawn from a list of all regular primary and secondary schools in the Netherlands, which was stratified by urbanity level to ensure population representativeness [30]. At the time data were collected, no ethical approval was deemed necessary as data-collection was perceived as non-intrusive for adolescents. As times have changed, we gained ethical approval from the Ethics Assessment Committee of the Faculty of Social Sciences at Utrecht University (FETC17-079 in 2017) for the Dutch HBSC study. Informed consent was obtained from schools, participants, and their parents, and participation was voluntary. Anonymity and confidentiality were guaranteed to all participants, and data-collection took place under exam conditions [30]. In total, 7168 adolescents from 78 primary schools and 67 secondary schools participated in the study; participants had a mean age of $13.7 \pm 1.6$ years, $50.5 \%$ was a girl, and the majority was of Dutch origin (78\%) (for more information about the sample, see Table 1). 


\section{Measures}

\section{Chronic disease of the adolescent and in the family}

Participants indicated whether they or one of their family members (sibling, parent) had a long-term ( $>3$ months) disease or disability (mental or physical). Based on their responses, all participants were categorized into four groups based on the presence of chronic disease within their family: none $(n=6195)$, other $(n=737)$, self $(n=162)$, both $(n=74)$.

\section{Demographic information and individual characteristics}

Self-reported data was collected for age, sex, ethnicity (based on the country of birth of the parents), living situation (with both parents or not), and participants' school level (primary school, vocational education, intermediate secondary education, higher secondary education, pre-university education). Family socio-economic status (SES) was assessed with the Family Affluence Scale (FAS), assessing family material prosperity [30, 31]. International studies have shown that the FAS is a valid and reliable measure of SES [31].

\section{Psychosocial functioning in different life domains}

To assess adolescent psychosocial functioning in a comprehensive manner, nine life domains were identified using various items and validated scales: life satisfaction, selfrated health, psychosomatic health, mental health, support, substance use, physical exercise, screen time, and school liking (for details about the wording, values and Cronbach's alpha, see Table 2).

Several of these instruments were validated in previous research. The Strengths and Difficulties Questionnaire (SDQ) distinguishes between hyperactivity-inattention, emotional symptoms, peer problems, and conduct problems. Previous research in Dutch samples showed measurement invariance of the SDQ subscales for different groups (i.e., boys/girls, immigrants/non-immigrants, adolescents with different educational levels) and acceptable internal consistency, test-retest stability, and concurrent validity $[32,33]$. An 8-item scale was used to assess psychosomatic health complaints. This instrument has good psychometric properties and has been validated as an unbiased measurement of subjective psychosomatic health complaints across age groups, sex, SES, and countries [34]. Moreover, the scales

Table 1 Sociodemographic and individual characteristics of the study population

\begin{tabular}{|c|c|c|c|c|c|c|}
\hline & Total $(n=7168)$ & None $(n=6195)$ & Other $(n=737)$ & Self $(n=162)$ & Both $(n=74)$ & \\
\hline Age, $M$ (SD) & $13.68(1.57)$ & $13.66(1.56)$ & $13.77(1.56)$ & $13.75(1.65)$ & $13.60(1.60)$ & $F=1.191, p=.311$ \\
\hline Sex, $n(\%)$ & & & & & & $\chi^{2}=11.829, p=.008$ \\
\hline Male & $3550(49.5 \%)$ & $3094(49.9 \%)$ & $330(44.8 \%)$ & $93(57.4 \%)$ & $33(44.6 \%)$ & \\
\hline Female & $3618(50.5 \%)$ & $3101(50.1 \%)$ & $407(55.2 \%)$ & $69(42.6 \%)$ & $41(55.4 \%)$ & \\
\hline Ethnicity, $n(\%)$ & & & & & & $\chi^{2}=20.368, p=.498$ \\
\hline Dutch & $5600(78.2 \%)$ & $4835(78.1 \%)$ & $569(77.2 \%)$ & $138(85.2 \%)$ & $58(78.4 \%)$ & \\
\hline Surinamese & $169(2.4 \%)$ & $140(2.3 \%)$ & $21(2.8 \%)$ & $5(3.1 \%)$ & $3(4.1 \%)$ & \\
\hline Antillean & $96(1.3 \%)$ & $82(1.3 \%)$ & $12(1.6 \%)$ & $2(1.2 \%)$ & $0(0 \%)$ & \\
\hline Moroccan & $192(2.7 \%)$ & $164(2.6 \%)$ & $25(3.4 \%)$ & $1(0.6 \%)$ & $2(2.7 \%)$ & \\
\hline Turkish & $238(3.3 \%)$ & $210(3.4 \%)$ & $23(3.1 \%)$ & $2(1.2 \%)$ & $3(4.1 \%)$ & \\
\hline Other Non-Western & $458(6.4 \%)$ & $406(6.6 \%)$ & $45(6.1 \%)$ & $6(3.7 \%)$ & $1(1.4 \%)$ & \\
\hline Other Western & $412(5.7 \%)$ & $355(5.7 \%)$ & $42(5.7 \%)$ & $8(4.9 \%)$ & $7(9.5 \%)$ & \\
\hline Living situation, $n(\%)$ & & & & & & $\chi^{2}=9.967, p=.019$ \\
\hline With both parents & $5348(74.6 \%)$ & $4654(75.1 \%)$ & $518(70.3 \%)$ & $125(77.2 \%)$ & $51(68.9 \%)$ & \\
\hline SES, $n(\%)$ & & & & & & $\chi^{2}=30.088, p<.001$ \\
\hline Low & $922(12.9 \%)$ & $780(12.6 \%)$ & $106(14.4 \%)$ & $21(13.0 \%)$ & $15(20.3 \%)$ & \\
\hline Middle & $3957(55.2 \%)$ & $3370(54.4 \%)$ & $456(61.9 \%)$ & $92(56.8 \%)$ & $39(52.7 \%)$ & \\
\hline High & $2289(31.9 \%)$ & $2045(33.0 \%)$ & $175(23.7 \%)$ & $49(30.2 \%)$ & $20(27 \%)$ & \\
\hline School level, $n(\%)$ & & & & & & $\chi^{2}=4.087, p=.906$ \\
\hline Primary school & $1597(22.3 \%)$ & $1391(22.5 \%)$ & $147(19.9 \%)$ & $39(24.1 \%)$ & $20(27 \%)$ & \\
\hline Vocational education & $1372(19.1 \%)$ & $1176(19 \%)$ & $146(19.8 \%)$ & $33(20.4 \%)$ & $17(23 \%)$ & \\
\hline Intermediate secondary education & $1511(21.1 \%)$ & $1297(20.9 \%)$ & $165(22.4 \%)$ & $36(22.2 \%)$ & $13(17.6 \%)$ & \\
\hline Higher secondary education & $1465(20.4 \%)$ & $1267(20.5 \%)$ & $152(20.6 \%)$ & $30(18.5 \%)$ & $16(21.6 \%)$ & \\
\hline Pre-university education & $1223(17.1 \%)$ & $1064(17.2 \%)$ & $127(17.2 \%)$ & $24(14.8 \%)$ & $8(10.8 \%)$ & \\
\hline
\end{tabular}


Table 2 Psychosocial life domains, corresponding HBSC items/subscales and internal consistency measurements

\begin{tabular}{|c|c|c|c|}
\hline Domain & Incorporated items/subscales & Values & $\begin{array}{l}\text { Cronbach's } \\
\text { alpha }\end{array}$ \\
\hline Life satisfaction & How do you feel about your life? & 0 (worst possible life) to 10 (best possible life) & N/A \\
\hline Self-rated health & What do you think of your own health? & Bad; reasonable; good; excellent & N/A \\
\hline Psychosomatic health & $\begin{array}{l}\text { In the last } 6 \text { months, how often have you had/felt: } \\
\text { - Headache } \\
\text { - Stomach ache } \\
\text { - Back ache } \\
\text { - Dizzy } \\
\text { - Difficulties getting to sleep } \\
\text { - Unhappy } \\
\text { - Moody } \\
\text { - Nervous }\end{array}$ & $\begin{array}{l}\text { About every day; more than once a week; about } \\
\text { every week; about every month; rarely or never }\end{array}$ & .798 \\
\hline \multirow[t]{4}{*}{ Mental health problems } & SDQ subscale conduct problems (5 items) & Range $0-10$ : higher score $=$ more problems & .475 \\
\hline & SDQ subscale hyperactivity-inattention ( 5 items) & Range 0-10: higher score $=$ more problems & .731 \\
\hline & SDQ subscale emotional problems (5 items) & Range $0-10$ : higher score $=$ more problems & .702 \\
\hline & SDQ subscale peer problems ( 5 items) & Range $0-10$ : higher score $=$ more problems & .470 \\
\hline \multirow[t]{2}{*}{ Support } & HBSC subscale support at home (4 items) & Range 1-7: higher score $=$ more support at home & .901 \\
\hline & HBSC subscale support from friends (4 items) & $\begin{array}{l}\text { Range 1-7: higher score }=\text { more support from } \\
\text { friends }\end{array}$ & .927 \\
\hline Substance use & $\begin{array}{l}\text { - Lifetime prevalence smoking } \\
\text { - Lifetime prevalence cannabis } \\
\text { - Monthly prevalence alcohol (in the last } 30 \text { days) }\end{array}$ & Yes or no & .710 \\
\hline Physical exercise & $\begin{array}{l}\text { Over the past } 7 \text { days, on how many days were you } \\
\text { physically active for a total of at least } 60 \mathrm{~min} \\
\text { per day? }\end{array}$ & $0-7$ days & N/A \\
\hline Screen time & $\begin{array}{l}\text { - About how many hours a day do you usually } \\
\text { watch television in your free time? } \\
\text { - About how many hours a day do you usually play } \\
\text { games on a computer or game console in your } \\
\text { free time? }\end{array}$ & $\begin{array}{l}\text { None at all; about half an hour a day; about } 1 \mathrm{~h} \mathrm{a} \\
\text { day; about } 2 \mathrm{~h} \text { a day; about } 3 \mathrm{~h} \text { a day; about } 4 \mathrm{~h} \\
\text { a day; about } 5 \mathrm{~h} \text { a day; about } 7 \text { or more hours } \\
\text { a day }\end{array}$ & .809 \\
\hline School liking & How do you feel about school at present? & $\begin{array}{l}\text { I don't like it at all; I don't like it very much; I } \\
\text { like it a bit; I like it a lot }\end{array}$ & N/A \\
\hline
\end{tabular}

on experienced support from family and friends showed good internal reliability, good test-retest reliability, and moderate construct validity in previous studies-also among adolescents and populations with chronic disease [35, 36].

\section{Statistical analysis}

All analyses were performed using SPSS for Macintosh version 24.0 (IBM, Armonk, NY). To assess (demographic) differences between the different groups established based on the presence of a chronic disease, $\chi^{2}$ tests were performed for categorical data (sex, ethnicity, living situation, SES, and school level) and one-way analysis of variance (ANOVA) for continuous data (age). The variables for which differences were found were included as control variables in the subsequent analyses. Next, to examine differences between the four groups regarding their psychosocial functioning in the different life domains, univariate analyses of variance were performed. To facilitate the interpretation of significant outcomes between the groups, estimated marginal means were used to obtain pairwise comparisons of all groups.
Bonferroni adjusted probabilities were used for all pairwise comparisons. Subsequently, mean differences, standard errors for the differences, and $95 \%$ confidence interval for all comparisons were assessed. Z-scores were calculated to enable (graphic) comparison of the different domains by standardizing the distributions.

\section{Results}

Table 1 presents the sociodemographic and individual characteristics for the four groups. All four groups were comparable with respect to age, ethnicity and school level. We observed a significant difference in terms of sex $\left(\chi^{2}=11.829\right.$, $p=0.008)$, living situation $\left(\chi^{2}=9.967, p=0.019\right)$, and SES $\left(\chi^{2}=30.088, p<0.001\right)$. Therefore, sex, living situation, and SES were added as potential confounders in all analyses. The results from the analyses of variance assessing differences in psychosocial functioning between four groups of chronic disease are reported in Table 3 and are visualized with $z$-scores and error bars in Fig. 1. The effect sizes $\left(\eta^{2} \sim 0.01\right)$ 
are consistent across several domains at the cost of adolescents who (indirectly) grow up with chronic disease, which underlines the clinical relevance of our analyses.

\section{Life satisfaction and self-rated health}

All adolescents who grew up with chronic disease (other, self, both) reported significantly poorer outcomes in terms of life satisfaction and self-rated health compared to their healthy peers (none). Nevertheless, adolescents who had a chronic disease themselves and had a family member with a chronic disease (both) reported significantly lower life satisfaction compared to adolescents who had a chronically diseased family member (other). For self-rated health, our findings showed that the two groups of adolescents who had a chronic disease themselves (self, both) view their health significantly worse than those who grew up with a chronically diseased family member (other).

\section{Psychosomatic health}

Psychosomatic health complaints were reported significantly more among all adolescents who grew up with chronic disease (other, self, both) as compared to their healthy peers (none). Moreover, our findings indicate that adolescents who had a chronic disease themselves (self, both) reported even more psychosomatic health complaints than healthy adolescents who grew up with a chronically diseased family member (other).

\section{Mental health}

Generally, adolescents who grew up with chronic disease (other, self, both) reported significantly more conduct problems, hyperactivity-inactivity, emotional problems, and peer problems than their healthy peers (none). The only exception was conduct problems, for which no differences between healthy adolescents (none) and those with a family member with chronic disease (other) were found. Adolescents who had a chronic disease themselves and had a family member with a chronic disease (both) reported more problems on all four indicators of mental health than adolescents in the other group. Adolescents who had a chronic disease themselves (self) reported similarly as adolescents in the both group; only for peer problems the latter (both) reported more problems than the former (self) group.

\section{Support}

For support, results showed a different pattern than for the abovementioned (mental) health indicators. In terms of family support, adolescents with a family member with a chronic disease (other) showed significantly poorer outcomes compared to their healthy peers (none), while no differences were found between the other groups of adolescents. When assessing peer support, adolescents with a chronic disease themselves (self) reported significantly worse outcomes than their healthy peers (none). Again, no differences between the other groups were revealed.

\section{Lifestyle factors and school liking}

Adolescents who grew up with a chronic disease (self) scored significantly poorer on physical exercise compared to all other groups (none, other, both), as well as in terms of substance use (alcohol, smoking, cannabis) compared to their healthy peers (none). With regards to screen time and school liking, we did not find significant differences between any of the groups.

\section{Discussion}

The purpose of this study was to assess the psychosocial functioning of adolescents who grow up with (a family member with) a chronic disease. Psychosocial functioning across a range of life domains were compared between adolescents who were (directly and/or indirectly) exposed to chronic disease and healthy adolescents in healthy families. Our results showed that adolescents with a chronic disease themselves (self) had decrements in many life domains. More specifically, and in line with former research, they reported lower life satisfaction, self-rated health and psychosomatic health, more conduct problems, hyperactivity-inactivity, emotional problems and peer problems, lower peer support, more substance use, and less physical exercise when compared to their healthy peers. Chronically diseased adolescents who also had a chronically diseased family member (both) showed similar scores across all life domains as adolescents with a chronic disease themselves (self), although it must be noted that no differences in peer support, substance use, and physical exercise between the former group and the group of healthy peers were found. These findings suggest that there is no additional risk for impaired psychosocial functioning when an adolescent with a chronic disease also has a chronically diseased family member (sibling or parent). However, this does not mean that having a chronically diseased family member is not associated with less optimal outcomes. Although healthy adolescents with a chronically diseased family member (other) often reported more positive outcomes than the groups of adolescents with a chronic disease (self, both), significantly lower life satisfaction, self-rated and psychosomatic health, more hyperactivity-inactivity, emotional problems and peer problems, and less family support were found in this group as compared to healthy peers in healthy families (none). 


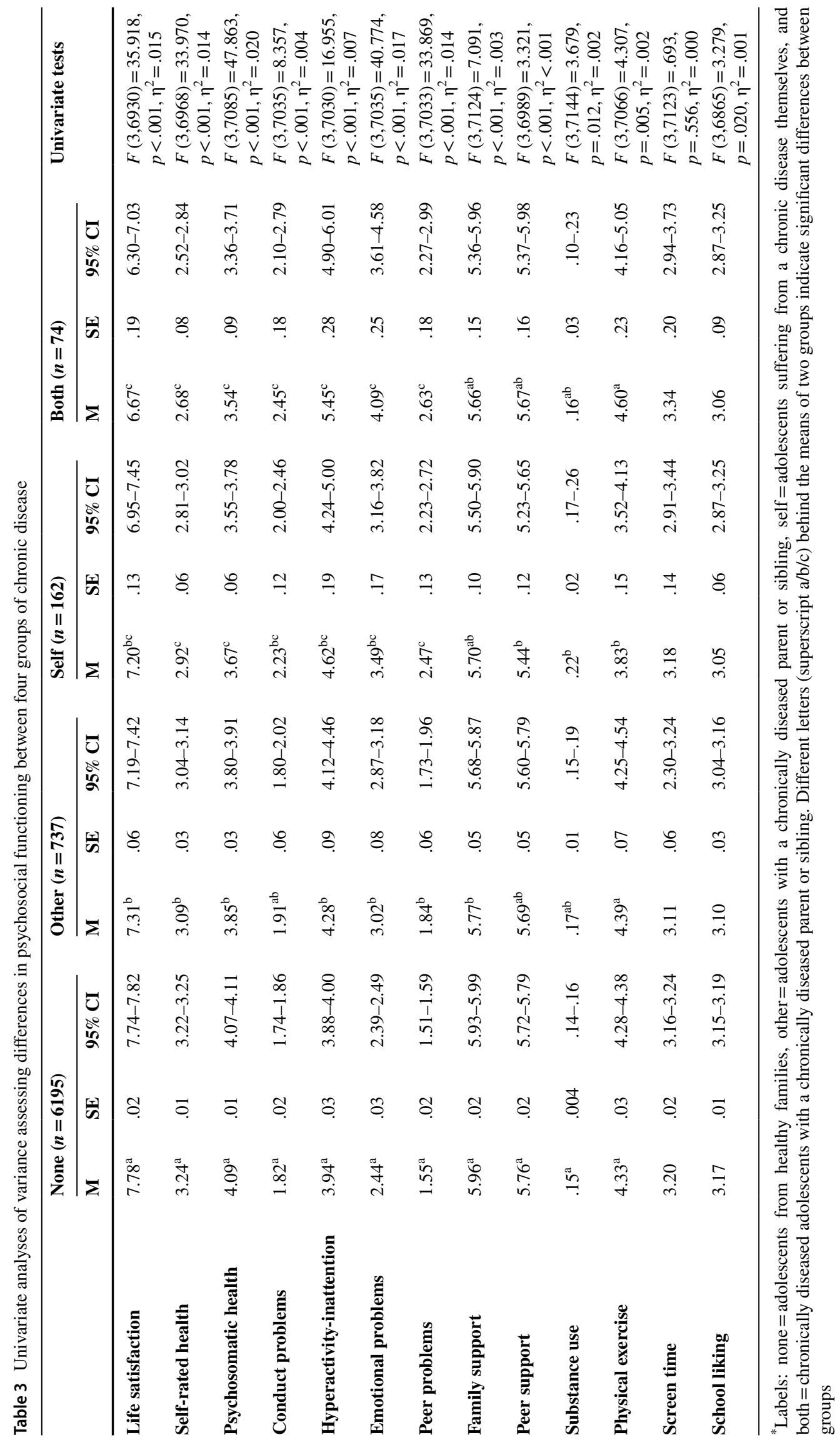




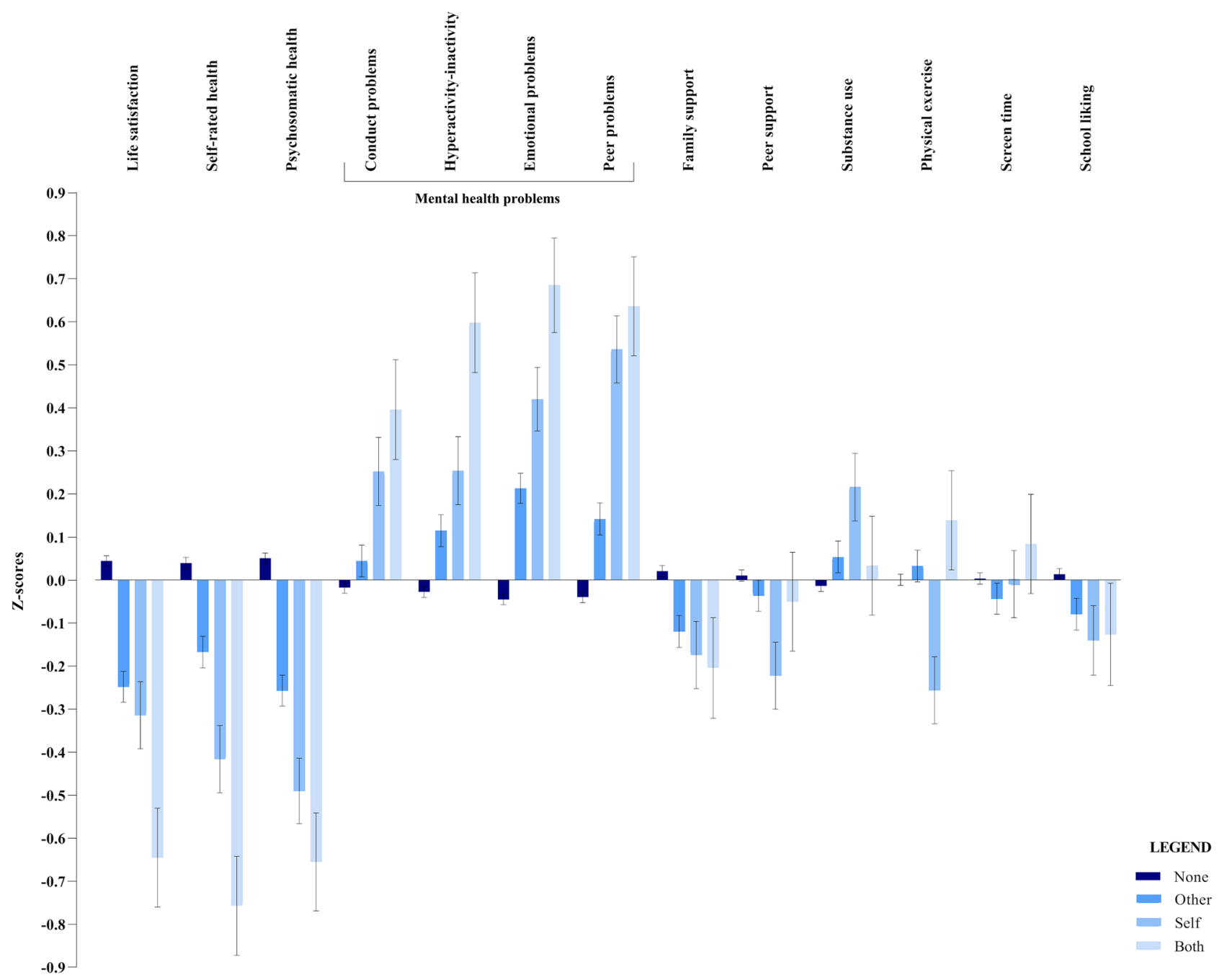

Fig. 1 Average z-scores and error bars showing the self-reported psychosocial functioning per life domain among adolescents growing up with chronic disease

Our results show that growing up with a chronic disease in adolescence is associated with impaired psychosocial functioning. The decremental psychosocial associates of chronic disease may be related to a great range of factors that have been studied previously. Foremost, having a chronic disease exposes the adolescent to numerous physical, emotional, psychological, and social challenges [9, 12, 37]. Due to their disease, adolescents may be unable to fully participate in school, leisure activities, or social events, which may go hand in hand with an increased incidence of psychological adjustment problems, lower selfesteem, stress, and stigmatization [9, 38, 39]. These challenges may be particularly prominent during adolescence, as one of the most important developmental demands in adolescence is to become independent of one's parents and to develop peer relationships. The aforementioned problems within various life domains may impede normal functioning and development but may also persist beyond adolescence, thereby posing a risk for physical, emotional and social well-being across the lifespan [10]. Hereby, the need to prevent chronic disease where possible and promote healthy behavior among adolescents is emphasized. Furthermore, caregivers should-next to the physical aspects of a disease-be aware and observant of the psychosocial problems that their patients may encounter, and development of preventative interventions that nourish psychosocial wellbeing and resilience may be of great value [10, 40].

In addition to having a chronic disease oneself, having a family member (sibling or parent) with a chronic disease was associated with less optimal psychosocial functioning, even if the adolescents did not suffer from a disease themselves. This apparent spillover effect has been previously linked to the emotional impact, increased amount of physical, social 
and financial stress, lack of attention or guidance (caregiving), altered roles within the family, and limited resources $[17,21,26,29]$. In line with the finding that these adolescents reported lower family support than their healthy peers, these adolescents may take on a caregiver role early on in life, which may be accompanied with emotional challenges, withhold them from engaging in normal daily-life activities, and complicate interactions with peers [26, 41]. In future studies, it would be interesting to further investigate the differences between having a mother, father, or sibling with a chronic disease. Remarkably, girls more often report having a chronically diseased family member, which may be related with gender-specific differences, such as individual characteristics (sensitivity to signals of need for care), family roles, or tendency to report others' chronic disease [41, 42]. In order to safeguard normal development of adolescents and provide adequate support when necessary, caregivers should be attentive to the potential impact of growing up with chronically diseased family member [41].

Even though adolescents who were confronted with chronic disease on average scored worse on most life domains compared to their healthy peers, we also observed considerable variance, especially in the group where both the adolescent and a family member suffered from a chronic disease (both). It is vital to further study which adolescents are specifically at higher risk to lag behind in comparison to their peers or experience increased distress. Differences across and within patient populations may help us to understand what determines an individual's risk or resilience to the psychosocial impact of chronic disease.

To our knowledge, this is the first study to evaluate the self-reported psychosocial functioning of adolescents with a (family member with a) chronic disease by comparing psychosocial functioning of healthy adolescents with that of adolescents with a chronic disease themselves and/or within the family. The sample is representative for the Dutch population and provides insight into various life domains by means of frequently used and validated measures. However, this study also has several limitations. Given its cross-sectional design, causal conclusions cannot be drawn. Especially since chronic diseases may also primarily affect mental health, impaired self-reported psychosocial functioning may be a consequence and/or a predicting factor of chronic disease. Future longitudinal research is warranted to shed more light into this potentially bidirectional association. Also, the risks that adolescents with a (family member with a) chronic disease show in different life domains may be interrelated, e.g. adolescents may report lower life satisfaction because they reported more mental health problems. Furthermore, no information was obtained about the type of chronic disease adolescents or their family members suffered from. Associations between chronic disease and psychosocial functioning may vary according to the type of chronic disease, as specific diseases vary considerably on aspects that shape and differentially affect adolescent functioning (e.g., life-threatening, physical disability, mental health problems) [10, 28]. Future research should be performed to assess whether the observed patterns differ among specific (patient) populations. Also, the proportion of adolescents who reported to grow up with a chronic disease in our sample was considerably lower (3.3\%) than estimated by medical caretakers $(26.2 \%)[1,6,37]$. From our results, we can conclude that perceiving oneself as chronically ill is associated with impaired psychosocial functioning on various life domains. Thus, one might be able to distinguish a group that is more vulnerable as compared to healthy peers by assessing self-reported presence of chronic illness. Future research should evaluate the association between 'objective' chronic disease as assessed by physicians and adolescents' perception of a chronic disease, and which factors influence discrepancies between both. Moreover, several domains that may affect psychosocial functioning among adolescents (with a chronic disease)—such as school functioning, resilience, and sleep-were not assessed as they were not incorporated in the HBSC questionnaire. It would be interesting to further explore these aspects in future studies. Lastly, the study only included participants who were able to attend school. Given that at least some adolescents with a chronic disease may not be present or attend special education, this may impede the external validity of our study. Follow-up studies should therefore attempt to obtain more information regarding the chronic disease type and duration, and to include patients who may not be able to attend school as well.

\section{Conclusion}

The present study provides evidence that having a (family member with a) chronic disease is associated with impaired psychosocial functioning on various life domains. We found that chronically diseased adolescents (self) reported significantly lower life satisfaction, self-rated health and psychosomatic health, more mental health problems, lower peer support, more substance use, and less physical activity when compared to healthy peers. Moreover, chronically diseased adolescents who also had a chronically diseased family member (both) showed comparable outcomes on most of these life domains. Lastly, we found evidence of a spillover effect of growing up healthy with a chronically diseased family member (other), as these adolescents reported significantly lower life satisfaction, self-rated health and psychosomatic health, more mental health problems, and less family support compared to their healthy peers who grew up in healthy families (none). Our findings 
may aid in understanding the psychosocial associates of chronic disease and imply that-in order to safeguard healthy development-caregivers should be observant of psychosocial problems among adolescents who (indirectly) grow up with chronic disease.

\begin{abstract}
Authors' contributions Drs. Berkelbach van der Sprenkel was responsible for conducting and interpreting the analyses, and drafted the manuscript. Dr. Stevens, Dr. Nijhof, and Prof.dr. Finkenauer conceptualized and designed the study, supervised the data-analysis, and contributed to drafting of the initial manuscript. Dr. Dalmeijer, Dr. Onland-Moret, Dr. de Roos, Dr. Lesscher, Prof. dr. van de Putte, and Prof. dr. van der Ent contributed to interpretation of the data and critically revised the manuscript for important intellectual content. All authors approved the final manuscript as submitted and agree to be accountable for all aspects of the work.
\end{abstract}

Funding This research did not receive any specific grant from funding agencies in the public, commercial, or not-for-profit sectors. The authors have no financial relationships relevant to this article to disclose.

Data availability The data is available for external use by agreement with the HBSC International Coordinator and the Principal Investigators. Information on how to request further data can be found on www. hbsc.org.

Code availability Not applicable.

\section{Declarations}

Ethics approval At the time data were collected, no ethical approval was deemed necessary as data-collection was perceived as non-intrusive for adolescents. As times have changed, we gained ethical approval from the Ethics Assessment Committee of the Faculty of Social Sciences at Utrecht University (FETC17-079 in 2017) for the Dutch HBSC study.

Consent for publication Informed consent was obtained from schools, participants and their parents, and participation was voluntary.

Competing interests The authors declare no competing interests.

Open Access This article is licensed under a Creative Commons Attribution 4.0 International License, which permits use, sharing, adaptation, distribution and reproduction in any medium or format, as long as you give appropriate credit to the original author(s) and the source, provide a link to the Creative Commons licence, and indicate if changes were made. The images or other third party material in this article are included in the article's Creative Commons licence, unless indicated otherwise in a credit line to the material. If material is not included in the article's Creative Commons licence and your intended use is not permitted by statutory regulation or exceeds the permitted use, you will need to obtain permission directly from the copyright holder. To view a copy of this licence, visit http://creativecommons.org/licenses/by/4.0/.

\section{References}

1. Perrin JM, Bloom SR, Gortmaker SL (2007) The increase of childhood chronic conditions in the United States. J Am Med Assoc 297:2755-2759. https://doi.org/10.1001/jama.297.24.2755
2. Brinkman TM, Recklitis CJ, Michel G et al (2018) Psychological symptoms, social outcomes, socioeconomic attainment, and health behaviors among survivors of childhood cancer: current state of the literature. J Clin Oncol 36:2190-2197. https://doi. org/10.1200/JCO.2017.76.5552

3. Stephenson AL, Tom M, Berthiaume Y et al (2015) A contemporary survival analysis of individuals with cystic fibrosis: a cohort study. Eur Respir J 45:670-679. https://doi.org/10.1183/ 09031936.00119714

4. Wise PH (2007) The future pediatrician: the challenge of chronic illness. J Pediatr 151. https://doi.org/10.1016/j.jpeds.2007.08.013

5. Van Cleave J (2010) Dynamics of Obesity and Chronic Health Conditions Among Children and Youth. JAMA 303:623. https:// doi.org/10.1001/jama.2010.104

6. van Hal L, Tierolf B, van Rooijen M et al (2019) A current perspective on children and young people with a chronic condition in the Netherlands: size, composition and participation [Een actueel perspectief op kinderen en jongeren met een chronische aandoening in Nederland: omvang, samenstelling en participatie]. Retrieved from: https://www. verwey-jonker.nl/publicatie/een-actueel-perspectief-op-kinderen-enjongeren-met-een-chronische-aandoening-in-nederland-omvangsamenstelling-en-participatie/

7. Murray CJL, Richards MA, Newton JN et al (2013) UK health performance: findings of the Global Burden of Disease Study 2010. Lancet 381:997-1020. https://doi.org/10.1016/S01406736(13)60355-4

8. Barlow JH, Ellard DR (2006) The psychosocial well-being of children with chronic disease, their parents and siblings. An overview of the research evidence base. Child Care Health Dev 32:19-31. https://doi.org/10.1111/j.1365-2214.2006.00591.x

9. Suris JC, Michaud PA, Viner R (2004) The adolescent with a chronic condition. Part I: developmental issues. Arch Dis Child 89:938-942. https://doi.org/10.1136/adc.2003.045369

10. Maurice-Stam H, Nijhof SL, Monninkhof AS et al (2019) Review about the impact of growing up with a chronic disease showed delays achieving psychosocial milestones. Acta Paediatr Int J Paediatr 108:2157-2169. https://doi.org/10.1111/apa.14918

11. Burns JJ, Sadof M, Kamat D (2007) The adolescent with a chronic illness: epidemiology, developmental issues and health care provision. World Heal Organ 35(206-210):214-216. https://doi.org/10. 1136/adc.2003.045377

12. Pinquart M (2014) Achievement of developmental milestones in emerging and young adults with and without pediatric chronic illness-a meta-analysis. J Pediatr Psychol 39:577-587. https://doi. org/10.1093/jpepsy/jsu017

13. Martinez W, Carter JS, Legato LJ (2011) Social competence in children with chronic illness: a meta-analytic review. J Pediatr Psychol 36:878-890. https://doi.org/10.1093/jpepsy/jsr035

14. Pinquart M, Teubert D (2012) Academic, physical, and social functioning of children and adolescents with chronic physical illness: a meta-analysis. J Pediatr Psychol 37:376-389. https://doi. org/10.1093/jpepsy/jsr106

15. Emerson ND, Distelberg B, Morrell HER et al (2016) Quality of life and school absenteeism in children with chronic illness. J Sch Nurs 32:258-266. https://doi.org/10.1177/1059840515615401

16. Pinquart M, Shen Y (2011) Behavior problems in children and adolescents with chronic physical illness: a meta-analysis. J Pediatr Psychol 36:1003-1016. https://doi.org/10.1093/jpepsy/jsr042

17. Golics CJ, Khurshid M, Basra A et al (2013) The impact of patients' chronic disease on family quality of life: An experience from 26 specialties. Int J Gen Med 6:787-798. https://doi.org/10. 2147/IJGM.S45156

18. Cousino MK, Hazen RA (2013) Parenting stress among caregivers of children with chronic illness: a systematic review. J Pediatr Psychol 38:809-828. https://doi.org/10.1093/jpepsy/jst049 
19. De Roos SA, De Boer AH, Bot SM (2017) Well-being and need for support of adolescents with a chronically ill family member. J Child Fam Stud 26:405-415. https://doi.org/10.1007/ s10826-016-0574-7

20. East PL (2010) Children's provision of family caregiving: benefit or burden? Child Dev Perspect 4:55-61. https://doi.org/10.1111/j. 1750-8606.2009.00118.x

21. Bell MF, Bayliss DM, Glauert R, Ohan JL (2019) Developmental vulnerabilities in children of chronically ill parents: a populationbased linked data study. J Epidemiol Community Health 73:393400. https://doi.org/10.1136/jech-2018-210992

22. Sieh DS, Visser-Meily JMA, Meijer AM (2013) Differential outcomes of adolescents with chronically ill and healthy parents. J Child Fam Stud 22:209-218. https://doi.org/10.1007/ s10826-012-9570-8

23. Houck CD, Rodrigue JR, Lobato D (2006) Parent-adolescent communication and psychological symptoms among adolescents with chronically ill parents. J Pediatr Psychol 32:596-604. https://doi. org/10.1093/jpepsy/js1048

24. Sieh DS, Meijer AM, Oort FJ et al (2010) Problem behavior in children of chronically ill parents: a meta-analysis. Clin Child Fam Psychol Rev 13:384-397. https://doi.org/10.1007/s10567-010-0074-Z

25. Moffat AK, Redmond G (2017) Is having a family member with chronic health concerns bad for young people's health? Crosssectional evidence from a national survey of young Australians. BMJ Open 7:1-10. https://doi.org/10.1136/bmjopen-2016-013946

26. Higgins KS, Birnie KA, Chambers CT et al (2015) Offspring of parents with chronic pain: a systematic review and meta-analysis of pain, health, psychological, and family outcomes. Pain 156:22562266. https://doi.org/10.1097/j.pain.0000000000000293

27. Sharpe D, Rossiter L (2002) Siblings of Children With a Chronic Illness: A Meta-Analysis. J Pediatr Psychol 27:699-710. https:// doi.org/10.1093/jpepsy/27.8.699

28. Vermaes IPR, Van Susante AMJ, Van Bakel HJA (2012) Psychological functioning of siblings in families of children with chronic health conditions: a meta-analysis. J Pediatr Psychol 37:166-184. https://doi.org/10.1093/jpepsy/jsr081

29. Deavin A, Greasley P, Dixon C (2018) Children's perspectives on living with a sibling with a chronic illness. Pediatrics 142:e20174151. https://doi.org/10.1542/peds.2017-4151

30. Looze M, de Dorsselaer S, van Roos S, de Verdurmen J, Stevens G, Gommans R, Bon-Martens M, van Bogt T, ter Voolebergh W (2014) Gezondheid, welzijn en opvoeding van jongeren in Nederland: HBSC-2013: Health Behavior in School-aged Children

31. Currie C, Molcho M, Boyce W et al (2008) Researching health inequalities in adolescents: the development of the health behaviour in school-aged children (HBSC) Family Affluence Scale. Soc Sci Med 66:1429-1436. https://doi.org/10.1016/j.socscimed.2007.11.024
32. Muris P, Meesters C, van den Berg F (2003) The strengths and difficulties questionnaire (SDQ). Eur Child Adolesc Psychiatry 12:1-8. https://doi.org/10.1007/s00787-003-0298-2

33. Duinhof EL, Stevens GWJM, van Dorsselaer S et al (2015) Tenyear trends in adolescents' self-reported emotional and behavioral problems in the Netherlands. Eur Child Adolesc Psychiatry 24:1119-1128. https://doi.org/10.1007/s00787-014-0664-2

34. Ravens-Sieberer U, Erhart M, Torsheim T et al (2008) An international scoring system for self-reported health complaints in adolescents. Eur J Public Health 18:294-299. https://doi.org/10. 1093/eurpub/ckn001

35. De Maria M, Vellone E, Durante A, Biagioli VMM (2018) Psychometric evaluation of the Multidimensional Scale of Perceived Social Support (MSPSS) in people with chronic diseases. Ann Ist Super Sanità 54:308-315. https://doi.org/10.4415/ANN_18_04_07

36. Zimet GD, Powell SS, Farley GK et al (1990) Psychometric characteristics of the multidimensional scale of perceived social support. J Pers Assess 55:610-617. https://doi.org/10.1080/00223891.1990. 9674095

37. Mokkink LB, van der Lee JH, Grootenhuis MA et al. Prevalence and consequences of chronic illness among children [Omvang en gevolgen van chronische aandoeningen bij kinderen]. Tijdschrift voor kindergeneeskunde 75:154-158. https://doi.org/10.1007/BF03061684

38. Nijhof SL, Vinkers CH, van Geelen SM et al (2018) Healthy play, better coping: the importance of play for the development of children in health and disease. Neurosci Biobehav Rev. https://doi. org/10.1016/J.NEUBIOREV.2018.09.024

39. Lavigne JV, Faier-Routman J (1992) Psychological adjustment to pediatric physical disorders: a meta-analytic review1. J Pediatr Psychol 17:133-157. https://doi.org/10.1093/jpepsy/17.2.133

40. Secinti E, Thompson EJ, Richards M, Gaysina D (2017) Research review: childhood chronic physical illness and adult emotional health — a systematic review and meta-analysis. J Child Psychol Psychiatry Allied Discip 58:753-769. https://doi.org/10.1111/ jcpp. 12727

41. Chikhradze N, Knecht C, Metzing S (2017) Young carers: growing up with chronic illness in the family - a systematic review 2007-2017. J Compassionate Heal Care 4:1-16. https://doi.org/ 10.1186/s40639-017-0041-3

42. de Roos S, van Tienen I, de Boer A (2020) Bezorgd naar school - Kwaliteit van leven van scholieren met een langdurig ziek gezinslid. ISBN: 978903770939 1. Retrieved from: https://www. scp.nl/publicaties/publicaties/2020/02/12/bezorgd-naar-school

Publisher's Note Springer Nature remains neutral with regard to jurisdictional claims in published maps and institutional affiliations.

\section{Authors and Affiliations}

\section{Emma E. Berkelbach van der Sprenkel ${ }^{1}$ (D) Sanne L. Nijhof ${ }^{1}$. Geertje W. Dalmeijer ${ }^{2}$ - N. Charlotte Onland-Moret ${ }^{2}$. Simone A. de Roos ${ }^{3}$. Heidi M. B. Lesscher ${ }^{4}$. Elise M. van de Putte ${ }^{1}$. Cornelis K. van der Ent ${ }^{6}$. Catrin Finkenauer ${ }^{5}$. Gonneke W. J. M. Stevens ${ }^{5}$}

Emma E. Berkelbach van der Sprenkel e.e.berkelbachvandersprenkel@umcutrecht.nl

1 Department of Pediatrics, Wilhelmina Children's Hospital, University Medical Center, Utrecht University, Utrecht, The Netherlands
2 Julius Centre for Health Sciences and Primary Care, University Medical Center Utrecht, Utrecht University, Utrecht, The Netherlands

3 The Netherlands Institute for Social Research (SCP), Ministry of Health, Welfare and Sport, The Hague, The Netherlands 
4 Department of Animals in Science and Society, Division of Behavioural Neuroscience, Faculty of Veterinary Medicine, Utrecht University, Utrecht, The Netherlands

5 Department of Interdisciplinary Social Science, Faculty of Social and Behavioural Sciences, Utrecht University, Utrecht, The Netherlands
6 Department of Pediatric Pulmonology, Wilhelmina Children's Hospital, University Medical Center Utrecht, Utrecht University, Utrecht, The Netherlands 